\title{
Botulinum Toxin Type A Improves Function According to Goal Attainment in Adults with Poststroke Lower Limb Spasticity in Real Life Practice
}

\author{
Lourdes López de Munain ${ }^{a}$ Josep Valls-Soléb Irene Garcia Pascualc \\ Pascal Maisonobe $^{d}$ on behalf of the VALGAS investigators group \\ a Department of Rehabilitation, Hospital Universitario Marqués de Valdecilla, Santander, Spain; ${ }^{\mathrm{b}}$ Department of \\ Neurology, Hospital Clínic i Provincial de Barcelona, Barcelona, Spain; ' Ipsen Pharma, Medical Affairs, Barcelona, \\ Spain; 'Ipsen Pharma, Biometry, Boulogne-Billancourt, France
}

\section{Keywords}

Stroke $\cdot$ Spasticity $\cdot$ Type A botulinum toxin - Goal attainment scaling $\cdot$ Cohort study

\begin{abstract}
Introduction: Botulinum toxin type A (BoNT-A) is an effective and well-tolerated treatment for adult lower limb spasticity. However, data are inadequate to determine BoNT-A efficacy for active function. This study evaluated functional goal achievement (measured by goal attainment scaling [GAS]) following lower limb BoNT-A injection in clinical practice. Methods: Phase 4, postmarketing, multicenter, prospective, observational study (NCT01444794) in adults with poststroke lower limb spasticity receiving one BoNT-A injection cycle. Assessments were at baseline (pretreatment), 1 month \pm 7 days (visit 1 ), and 3-5 months posttreatment (visit 2). Primary outcome measure was GAS; additional assessments included Modified Ashworth Scale, Demeurisse Motricity Index, 10-meter walk test, and Disability Assessment Scale. Results: Of 100 enrolled patients, 94 completed the study. Most common primary treatment goals at baseline were improving mobility $(57.5 \%)$ and positioning (18.1\%). At visit 2, 88.3\% achieved their primary goal; $87.0 \%$
\end{abstract}

( $n=47 / 54)$ for mobility, and $100.0 \%(n=17 / 17)$ for positioning. In total, $79.1 \%$ of patients achieved their secondary goals. Two factors were predictive of primary goal achievement: time since stroke onset (OR 0.907; 95\% Cl 0.827-0.995; $p=0.038$ ); and absence of stiff knee spasticity pattern (OR $0.228 ; 95 \% \mathrm{Cl} 0.057-0.911 ; p=0.036$ ). All functional scales showed improvements; walking speed (mean [SD]) improved by $0.06(0.13)$ and $0.05(0.20) \mathrm{m} / \mathrm{s}$ at visits 1 and 2, respectively. Conclusions: BoNT-A injection for lower limb spasticity led to high goal achievement rates in patient-centered GAS evaluation and functional and symptomatic improvements. BoNT-A may therefore deliver clinically meaningful functional improvements in real-life practice.

@ 2019 The Author(s)
Published by S. Karger AG, Basel

\section{Introduction}

Stroke is the leading cause of disability in adults in Europe and the second most common cause of death worldwide, ranking ahead of cancer and only second to heart disease $[1,2]$. In Spain, there are 120-350 cases of stroke per 100,000 inhabitants each year [3]. The resulting central nervous system damage causes upper motor

\begin{tabular}{|c|c|}
\hline KARGER & $\begin{array}{l}\text { (c) } 2019 \text { The Author(s) } \\
\text { Published by S. Karger AG, Basel }\end{array}$ \\
\hline $\begin{array}{l}\text { E-Mail karger@karger.com } \\
\text { www.karger.com/ene }\end{array}$ & $\begin{array}{l}\text { This article is licensed under the Creative Commons Attribution- } \\
\text { NonCommercial-NoDerivatives } 4.0 \text { International License (CC BY- } \\
\text { NC-ND) (http://www.karger.com/Services/OpenAccessLicense). } \\
\text { Usage and distribution for commercial purposes as well as any dis- } \\
\text { tribution of modified material requires written permission. }\end{array}$ \\
\hline
\end{tabular}

Dr. Lourdes López de Munain

Department of Rehabilitation, Hospital Universitario Marqués de Valdecilla Servicio de Rehabilitación

C/Avda de Valdecilla No. 25, Pabellón 16 Bajo, ES-39008 Santander (Spain)

E-Mail lourdesmunain@gmail.com 
neuron syndrome, leading to loss of strength and skills; spasticity; and abnormal posture [4, 5]. At 12 months after a first stroke, $17-39 \%$ of patients have spasticity and this is disabling in up to $4 \%$ of cases $[6,7]$.

Lower limb spasticity, which commonly manifests as equinovarus foot deformity, is characterized by reduced ankle dorsiflexion and increased forefoot inversion [8]. In patients with lower limb spasticity after stroke, spastic equinus foot represents a prolonged abnormal lower limb posture and affects gait, standing, and transfer [9]. Muscles involved may include the tibialis anterior, tibialis posterior, the long toe flexors, medial and lateral gastrocnemius, soleus, and extensor hallucis longus [8].

Botulinum toxin type A (BoNT-A) is a specific formulation of a locally injected muscle relaxant produced by the bacterium Clostridium botulinum. BoNT-A blocks acetylcholine release at neuromuscular junctions, an action that accounts for its therapeutic effect in relieving dystonia and spasticity [10]. The integral role of BoNT-A in the management of focal spasticity is recognized in guidelines around the world [11-13].

BoNT-A has been established as safe and effective for the treatment of adult lower limb spasticity (multiple Class I studies) [14]. However, limited data are available to determine their efficacy in the improvement of active function [14]. Clinical research into the effects of BoNT-A in the lower limbs has focused mainly on deficits, such as muscle tone (measured using the Modified Ashworth Scale [MAS]) or range of movement. However, the goals of rehabilitation programs often involve different fields of the International Classification of Functioning, Disability and Health, such as activity, participation, quality of life, and environmental factors. A recent open-label study of abobotulinumtoxin A for the treatment of lower limb spasticity in adults demonstrated progressive improvements in active function and quality of life following repeated injections [15].

Goal attainment scaling (GAS) is a method for writing personalized evaluation scales, for quantifying progress toward defined goals. This approach is attracting growing interest in clinical practice because it enables the assessment of treatment efficacy based on goals set by the patient themselves, rather than using generic scales, which may not always include the problem that is most pertinent to the patient [16].

GAS can be used to cover all the fields of the International Classification of Functioning Disability and Health, including those relating to activity, participation, quality of life, and environmental factors. Involving the patient and their family and carers in the choice of treatment goals may enablebetterintegration into activities of dailyliving, by em- bedding these goals in the patient's usual context [16]. Patients undergoing rehabilitation are more motivated when their goals are clearly defined and consistent with their life project. Furthermore, rehabilitation outcomes are better when the patient is involved in setting their own goals [16].

To the best of our knowledge, real-world evidence on the application of GAS in the management of spasticity with BoNT-A has been only collected for the upper limb [17].

The aim of this study is to evaluate the achievement of goals agreed with the patient/caregiver (measured by GAS) in the treatment of lower limb spasticity with one cycle of BoNT-A injection, used in accordance with standard clinical practice. Secondary objectives are focused on assessing standardized measures of voluntary movement and ambulation, such as the 10-meterwalktest (10-MWT).

\section{Methods}

\section{Study Design}

We ran a multicenter, prospective, observational, longitudinal, single-cohort study (Valoración GAS [VALGAS]; NCT01444794), conducted in 23 neurology and rehabilitation departments in Spanish hospitals between September 2011 and August 2012. All patients received one cycle of BoNT-A injections. Patients were assessed at baseline (pre-BoNT-A treatment), at 1 month \pm 7 days (visit 1 ), and at 3-5 months post-treatment (visit 2; final visit). As the study is observational, it was designed to reflect, as accurately as possible, real-life clinical practice. Hence, investigators had complete freedom to choose target muscles, BoNT-A product, dose, volume, and number of injections per point.

The study was approved by the Spanish Medicine Agency as a post-authorization study with prospective follow-up. It was also approved by the Ethics Committees of all participating sites. $\mathrm{Pa}$ tients' personal data were confidential and delivered to third parties according to European Directive 95/46/CE on the protection of persons regarding personal data processing and Spanish Law 15/1999 on Personal Data Protection.

\section{Study Population}

Adults diagnosed with poststroke lower limb spasticity with no prior BoNT-A exposure, or exposure $>12$ weeks prior to study entry, were eligible for inclusion. In addition, all patients had a functional ambulation classification of 2-5. Treating physicians were required to confirm that patients were able to follow the study protocol and procedures.

Patients were excluded if they were under 18 years of age; had received BoNT-A for $<12$ weeks prior to study entry; had suspected botulinum toxin antigen positivity or had received any medication that could interfere with neuromuscular transmission; had any sign of motor neuron disease; had severe muscle atrophy at the injection site; had any other diagnosis that could impact on rehabilitation or outcome assessment; had any nonstroke-related spasticity; were pregnant or lactating women; or had previously participated in studies using GAS scores.

All participating patients provided written informed consent. 
Assessments

The primary outcome measure was response rate, based on achievement of the patient's primary GAS objective after one cycle of BoNT-A injection (GAS score at least 0 at visit 2). At baseline, one primary treatment goal and up to 2 secondary goals were set in agreement with the patient/caregivers. Goals were weighted based on their importance and difficulty (from very to moderately).

The achievement of goals was evaluated at visit 2, with scores of $+2,+1,0,-1$, or -2 given depending on the level of achievement. If the expected level of achievement was attained, a score of 0 was assigned. Better outcomes were scored +1 (better) or +2 (much better), and worse than expected outcomes were scored -1 (worse) or -2 (much worse) [18]. A responder was a patient who achieved a GAS score of at least 0 at visit 2 (final visit).

The T-score was used to enable GAS scores to be normalized and then analyzed with parametric statistics [16]. T-score was calculated by applying an equation that transforms the raw scores from the individual scales into a single number, $\mathrm{T}$ :

$$
T=50+\frac{10 \Sigma \mathrm{WiXi}}{\sqrt{\left[(1-\rho) \Sigma \mathrm{Wi}^{2}+\rho(\Sigma \mathrm{Wi})^{2}\right]}}
$$

where $\mathrm{Xi}$ is the GAS score, Wi is the weighting of each goal attainment scale, and rho is the correlation coefficient between the various scales [16]. If all goals have the same weight or the T-score is unweighted, this equation simplifies to:

$$
\mathrm{T}=50+\mathrm{C} \sum \mathrm{Xi}
$$

where $\mathrm{C}$ is a coefficient that depends on the patient's number of scales (and thus the number of scores). C is 10 for 1 scale, 6.2 for 2 scales, 4.56 for 3 scales, 3.63 for 4 scales, and 3.01 for 5 scales [16].

Muscle tone was evaluated using MAS, which is considered reliable for grading the resistance of a relaxed limb to rapid passive stretch in 6 stages: [19] from 0 , which indicates normal or lowered muscle tone, up to 4 , which indicates a state in which passive movement of the affected limb is impossible.

In addition to MAS, investigators and patients/caregivers were invited to complete a number of other assessment scales to provide a broader set of data points. These included the functional ambulation classification, Demeurisse Motricity Index, 10-MWT, Disability Assessment Scale, Spasm Frequency Scale, and the Tardieu Scale [20]. Completion of these scales was optional and was conducted according to local standard clinical practice.

Clinical and demographic parameters were also collected, as well as information on the BoNT-A injection dose, volume, injection sites, and the use of electromyography, electrical stimulation or echography at each center.

Statistical Analysis

A sample size of 100 patients was deemed sufficient to estimate the proportion of responders with $\geq 9.6 \%$ precision in the 95\% CI.

Statistical analysis was performed by the Biostatistics Department of Nuvisan Pharma Services, Spain, using SAS version 9.2 [21] following the procedures specified in the Statistical Analysis Plan prepared and approved before database lock. Descriptive statistics were applied to all demographic data. Prognostic factors were assessed with a logistic regression analysis.
Analyses were conducted on the primary analysis set $(n=94)$, comprising patients who received treatment and underwent a postinjection visit, including GAS assessment (Fig. 1). Analysis of the primary endpoint was also performed in a number of patient subgroups, including those with documented time since onset of spasticity.

\section{Results}

A total of 100 patients received treatment with BoNT-A for poststroke lower limb spasticity. One patient did not complete the study due to comorbidities (pancreatitis and heart failure) and 5 others did not complete a GAS assessment postinjection (Fig. 1). No other major deviations from the protocol were reported.

\section{Baseline Characteristics}

Baseline characteristics are provided in Table 1. The mean age (SD) of treated patients was 58.2 (12.5) years, and $65.0 \%$ were male. The most commonly reported lower extremity characteristics were increased muscle tone $(98.0 \%)$ and paresis (92.0\%; Table 1$)$; additionally, $29.0 \%$ of patients experienced contractures in the lower extremities. The most frequently reported spasticity pattern was clubfoot in $94 \%$ of patients; 22 and $21 \%$ of patients had striatal foot and stiff knee, respectively. Most patients were living in their own home $(71.0 \%)$, and $60.0 \%$ had a relative who took the role of caregiver. The majority of patients (93.0\%) had received prior physical therapy for spasticity. AbobotulinumtoxinA was the most commonly used BoNT-A (92.0\%), followed by onabotulinumtoxinA (6.0\%) and incobotulinumtoxinA (2.0\%; Table 1); median (range) doses injected were 250 units $(100 ; 1,000), 50$ units $(50 ; 250)$, and 100 units (100; $100)$, respectively. The median number of injected muscles was three. Electromyography and electrical stimulation were used in at least one muscle in 18.0 and $25.0 \%$ of patients, respectively. Altogether, $74.0 \%$ of patients received one single point injection in at least one muscle, and $85.0 \%$ of patients received injections at multiple points.

\section{GAS Goals}

At baseline, the most common primary goal of treatment was to improve mobility (57.5\%), followed by improving positioning (18.1\%; Table 2). Among secondary objectives, the most common goal set was to improve mobility (24.8\%), followed by improving positioning (19.4\%) and decreasing pain (17.8\%). 
Fig. 1. Patient disposition. BoNT-A, botulinum toxin type A; GAS, goal attainment scaling.

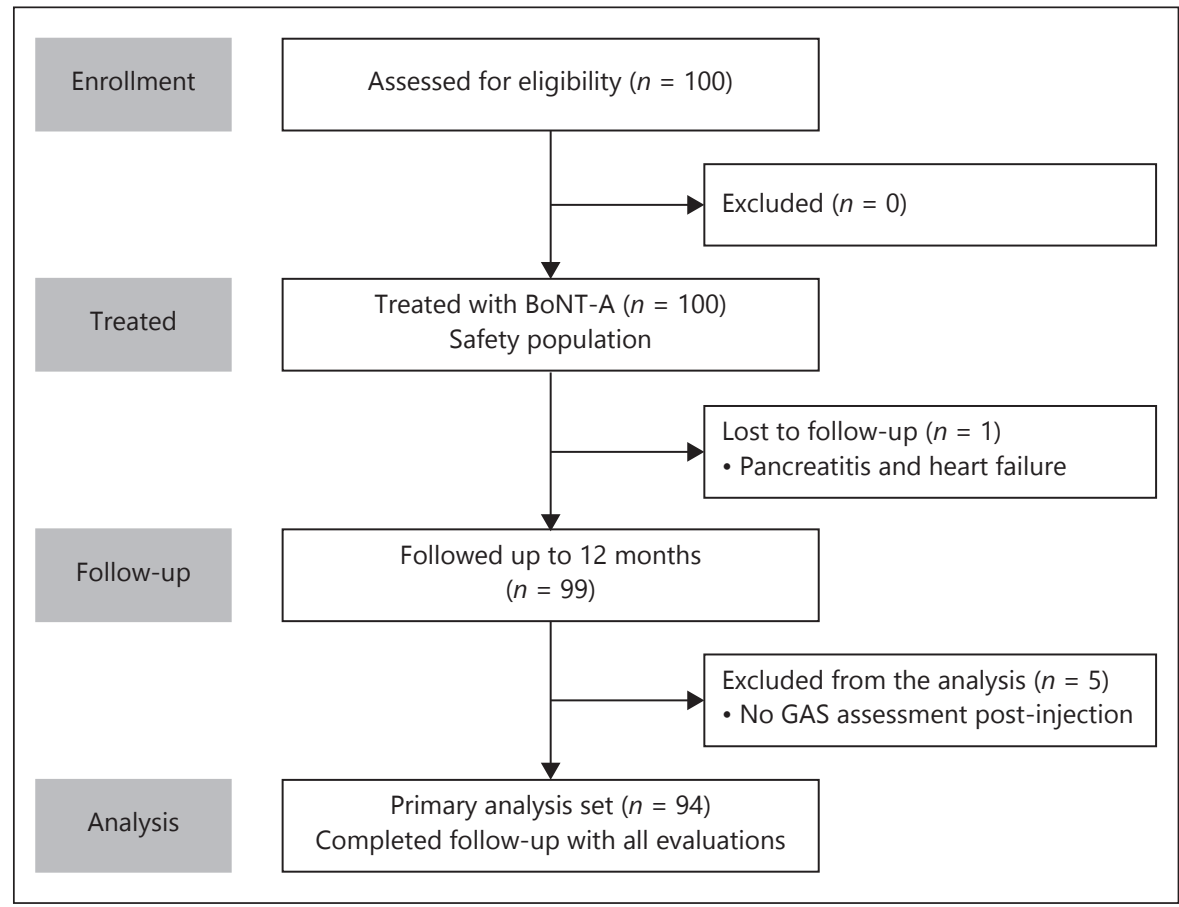

Muscle Tone, Functional Scales, and Benefit Evaluation

All scales demonstrated improvements in symptoms and function between baseline and study end (Table 3). Mean (SD) MAS decreased from $2.42(0.65)$ at baseline to $1.85(0.73)$ at visit 1 and $1.91(0.77)$ at visit 2; mean Demeurisse Motricity Total Score improved from 57.32 (17.01) at baseline to 61.23 (15.77) at visit 1 and 60.60 (17.37) at visit 2; the 10-MWT showed a mean improvement in walking speed of $0.06(0.13) \mathrm{m} / \mathrm{s}$ at visit 1 and 0.05 $(0.20) \mathrm{m} / \mathrm{s}$ at visit 2 ; there were also improvements in all 4 dimensions of the Disability Assessment Scale at visit 2. Patients also reported fewer spontaneous spasms on the Spasm Frequency Scale at study end compared with baseline.

A total of $81.7 \%$ of investigators and $78.5 \%$ of patients rated their global assessment of benefit to be "some" or "great."

\section{Discussion}

To the best of our knowledge, this is the first observational study to determine responder rate based on GAS in patients with lower limb spasticity. The study illustrated that in patients with poststroke lower limb spasticity, one cycle of BoNT-A administered according to the usual clin- 
ical practice of participating centers led to a high rate of achievement of primary and secondary objectives (88.3 and $79.1 \%$, respectively) using the GAS evaluation system.

If goals are set in an unbiased fashion, and are neither overambitious nor overcautious, the mean GAS T-score should be around $50( \pm$ SD 10) [22]. The mean (SD) GAS $\mathrm{T}$-score of 54.02 (10.36) at study end in the present work provides a useful quality check of investigators' ability to set achievable goals. Previous authors have suggested that GAS score changes $>10$ are clinically meaningful $[23,24]$. In this study, the mean improvement from baseline to study end was 17.84 (11.96).

Two predictive factors were identified for the attainment of objectives. A progressive decrease in objective attainment was observed with increasing years since the onset of spasticity. This was evidenced in a multiple logistic regression model, in which increasing time since the onset of stroke was associated with lower response rates. This is a logical finding and confirms similar results from previous studies [25-28]. The second predictive factor identified was the absence of a stiff knee, which could reflect the impact of this spasticity pattern on the difficulty of achieving the primary goal - most commonly improvement in mobility.

All symptom assessments and functional scales assessed showed clear improvements after one cycle of BoNT-A injections, including the MAS, Demeurisse Motricity Total Score, 10-MWT, and the Disability Assessment Scale. In addition, the Spasm Frequency Scale revealed that patients reported fewer spontaneous spasms at study end compared with baseline. All these measurements showed greater improvements at 1 month (visit 1) compared with 3-5 months post-BoNT-A injection (visit 2). This aligns with the known process of gradual recovery of impulse transmission from 6 to 8 weeks, as new nerve terminals sprout [29]. However, although the improvements were less marked at 3-5 months, there was still evidence of a good effect relative to baseline. In particular, improvement in walking speed (10-MWT) was notable. A systematic review and meta-analysis on the impact of BoNT-A treatment on gait velocity revealed a small improvement (Hedges' g $0.193 \pm 0.081 ; 95 \%$ CI $0.033-0.353$; $p<0.018$ ), equivalent to an increase of $0.044 \mathrm{~m} / \mathrm{s}$ [30]. Similarly, a recent study with repeat BoNT-A injections showed a progressive increase in comfortable barefoot walking speed across injection cycles, with a mean $(95 \% \mathrm{CI})$ improvement of +0.05 $(0.03-0.07)$ and $+0.04(0.03-0.06) \mathrm{m} / \mathrm{s}$ after a single injection of 1,000 or $1,500 \mathrm{U}$ abobotulinumtoxinA, respectively, followed by an overall least squares mean $(95 \% \mathrm{CI}) \mathrm{im}$ provement from baseline of $+25.35 \%(17.48-33.21)$ by
Table 1. Baseline patient, disease, and treatment characteristics

\begin{tabular}{|c|c|}
\hline Characteristic & $\begin{array}{l}\text { Patients } \\
(n=100), n(\%)\end{array}$ \\
\hline Age, years, mean (SD) & $58.2(12.5)$ \\
\hline \multicolumn{2}{|l|}{ Gender } \\
\hline Male & $65(65.0)$ \\
\hline Female & $35(35.0)$ \\
\hline \multicolumn{2}{|l|}{ Patient autonomy* } \\
\hline Lives in own home & $71(71.0)$ \\
\hline Lives with a relative as a caregiver & $43(43.0)$ \\
\hline Has the assistance of a relative as caregiver & $17(17.0)$ \\
\hline Time since stroke onset, years, mean (SD) & $4.1(5.3)$ \\
\hline \multicolumn{2}{|l|}{ Stroke type* } \\
\hline Ischemic & $64(64.0)$ \\
\hline Hemorrhagic & $40(40.0)$ \\
\hline \multicolumn{2}{|l|}{ Stroke sequelae* } \\
\hline Hemiparesis & $93(93.0)$ \\
\hline Impaired balance or coordination & $46(46.0)$ \\
\hline Depression & $33(33.0)$ \\
\hline Aphasia & $22(22.0)$ \\
\hline Time since spasticity onset, years, mean (SD) & $2.4(4.1)$ \\
\hline \multicolumn{2}{|l|}{ Upper extremity involvement } \\
\hline Yes & $89(89.0)$ \\
\hline No & $11(11.0)$ \\
\hline \multicolumn{2}{|l|}{ Lower extremity involvement (all)* } \\
\hline Ankle & $95(95.0)$ \\
\hline Foot & $81(81.0)$ \\
\hline Knee & $43(43.0)$ \\
\hline Hip & $20(20.0)$ \\
\hline \multicolumn{2}{|l|}{ Spasticity pattern* } \\
\hline Clubfoot & $94(94.0)$ \\
\hline Striatal foot & $22(22.0)$ \\
\hline Stiff knee & $21(21.0)$ \\
\hline \multicolumn{2}{|l|}{ Lower extremity characteristics* } \\
\hline Increased muscle tone & $98(98.0)$ \\
\hline Paresis & $92(92.0)$ \\
\hline Hypertonia & $81(81.0)$ \\
\hline Babinski sign & $81(81.0)$ \\
\hline Fatigue & $77(77.0)$ \\
\hline Loss of selective motion control & $75(75.0)$ \\
\hline \multicolumn{2}{|l|}{ Prior nondrug therapies for spasticity* } \\
\hline Physical therapy & $93(93.0)$ \\
\hline Antispastic positions & $65(65.0)$ \\
\hline Orthosis & $60(60.0)$ \\
\hline Muscular facilitation techniques & $54(54.0)$ \\
\hline Electrical stimulation & $15(15.0)$ \\
\hline Biofeedback & $11(11.0)$ \\
\hline \multicolumn{2}{|l|}{ Prior drug therapies for spasticity* } \\
\hline Botulinum toxin & $62(62.0)$ \\
\hline Baclofen & $31(31.0)$ \\
\hline Diazepam & $5(5.0)$ \\
\hline Tizanidine & $4(4.0)$ \\
\hline \multicolumn{2}{|l|}{ BoNT-A treatment } \\
\hline AbobotulinumtoxinA & $92(92.0)$ \\
\hline OnabotulinumtoxinA & $6(6.0)$ \\
\hline IncobotulinumtoxinA & $2(2.0)$ \\
\hline \multicolumn{2}{|l|}{ Functional ambulation category ${ }^{\dagger}$} \\
\hline 2 - walks with intermittent assistance by 1 person & $17(18.1)$ \\
\hline 3 - walks with monitoring. The patient needs & \\
\hline $\begin{array}{l}\text { verbal assistance without physical contact } \\
4 \text { - walks independently on plain paths, but does }\end{array}$ & $17(18.1)$ \\
\hline not climb stairs & $60(63.8)$ \\
\hline
\end{tabular}

All treated population.

* Responses were not mutually exclusive.

† Only assessed in the primary analysis set $(n=94)$.

BoNT-A, botulinum toxin type A. 
Table 2. Primary and secondary goal areas at baseline and achievement (PAS population)

\begin{tabular}{|c|c|c|c|c|}
\hline Goal area & $\begin{array}{l}\text { at baseline, } \\
N(\%)\end{array}$ & $\begin{array}{l}\text { achievement } \\
n / N(\%)\end{array}$ & $\begin{array}{l}\text { at baseline, } \\
N(\%)\end{array}$ & $\begin{array}{l}\text { achievement } \\
n / N(\%)\end{array}$ \\
\hline Better mobility & $54(57.5)$ & $47 / 54(87.0)$ & $32(24.8)$ & $24 / 32(75.0)$ \\
\hline Better positioning & $17(18.1)$ & $17 / 17(100.0)$ & $25(19.4)$ & $20 / 25(80.0)$ \\
\hline To decrease pain & $8(8.5)$ & $7 / 8(87.5)$ & $23(17.8)$ & $19 / 23(82.6)$ \\
\hline To enhance range of motion & $5(5.3)$ & $4 / 5(80.0)$ & $19(14.7)$ & $10 / 19(52.6)$ \\
\hline To delay or prevent surgery & $0(0)$ & $0 / 0(0)$ & $1(0.8)$ & $1 / 1(100.0)$ \\
\hline
\end{tabular}

PAS, primary analysis set; $N$, number of patients who set goal at baseline; $n$, number of patients who achieved their goal.

Table 3. Functional scales assessed as secondary objectives (PAS population, $n=94$ )

\begin{tabular}{|c|c|c|c|c|c|}
\hline & Baseline & mean value & $\begin{array}{l}\text { change from } \\
\text { baseline }\end{array}$ & mean value & $\begin{array}{l}\text { change from } \\
\text { baseline }\end{array}$ \\
\hline MAS, mean (SD) & $2.42(0.65)$ & $1.85(0.73)$ & $-0.55(0.65)$ & $1.91(0.77)$ & $-0.51(0.63)$ \\
\hline Demeurisse Motricity Total Score, mean (SD) & $57.32(17.01)$ & $61.23(15.77)$ & $2.69(9.00)$ & $60.60(17.37)$ & $3.28(11.59)$ \\
\hline 10-MWT, m/s, mean (SD) & $0.46(0.30)$ & $0.50(0.34)$ & $0.06(0.13)$ & $0.49(0.34)$ & $0.05(0.20)$ \\
\hline Dressing & $1.21(0.86)$ & & & $0.98(0.92)$ & $-0.22(0.67)$ \\
\hline Limb position & $1.33(0.76)$ & & & $1.02(0.91)$ & $-0.29(0.70)$ \\
\hline Pain & $0.91(0.87)$ & & & $0.53(0.68)$ & $-0.37(0.75)$ \\
\hline \multicolumn{6}{|l|}{ Spasm Frequency Scale, $n(\%)$} \\
\hline Spontaneous spasms & $11(18.6)$ & $\mathrm{N} / \mathrm{A}^{*}$ & $\mathrm{~N} / \mathrm{A}^{*}$ & $5(8.5)$ & \\
\hline
\end{tabular}

* This scale was optional at visit 1.

PAS, primary analysis set; N/A, not available; MAS, Modified Ashworth Scale; 10-MWT, 10-meter walk test.

week 4 of injection cycle 4 [15]. In our study, mean walking speed increased by $0.06 \mathrm{~m} / \mathrm{s}$ at 1 month and 0.05 at 3-5 months. Hence, the results align with previous data, supporting the notion that BoNT-A can increase gait velocity in patients with poststroke lower limb spasticity.

The mean number of patients recruited per center was only 4 , which is too low a number to reflect the diversity of patients treated at present with BoNT-A. However, a large number of centers involved in the study indicate a high degree of uniformity in clinical practice and support generalization of the findings in Spain. A similar percentage of investigators and patients rated their global assessment of benefit as "some" or "great." This may reflect the process of agreement between patients and healthcare providers in the setting of primary and secondary goals, providing a model for the evaluation of achievement in other studies.

Overall, this study confirms that patients treated with one cycle of BoNT-A injections (predominantly abobotulinumtoxinA) for lower limb spasticity had a high response rate, as measured by patient-centered goal attainment using GAS. Symptoms and function, measured using standardized scales, were also improved. Hence, BoNT-A treatment may deliver clinically meaningful improvements at a functional level in the treatment of spasticity in real-life practice. 


\section{Acknowledgments}

Members of the Spanish VALGAS Working Group included: Aguilar M, MD (Hospital Mútua de Terrasa, Barcelona); Bascuñana $\mathrm{H}, \mathrm{MD}$ (Hospital Sant Pau, Barcelona); Bori I, MD (Hospital Vall d'Hebrón, Barcelona); Colomer C, MD (Hospital Valencia al Mar, Valencia); Crespo MC, MD (Hospital Marítimo de Oza, A Coruña); Cutillas R, MD (Hospital Fundación Jiménez Díaz, Madrid); de León F, MD (Hospital Nuestra Señora de la Candelaria, Santa Cruz de Tenerife); Gant A, MD (Hospital la Princesa, Madrid); Grao C, MD (Hospital de Magdalena, Castellón); Juan FJ, MD (Hospital Xeral de Vigo, Vigo); Junyent J, MD (Hospital de Bellvitge, L'Hospitalet de Llobregat, Barcelona); López de Munaín L, MD (Hospital Marqués de Valdecilla, Santander); Lozano J, MD (Hospital Morales Meseguer, Murcia); Máñez I, MD (Hospital La Fe, Valencia); Martínez M, MD (Hospital La Paz, Madrid); Medina F, MD (Hospital Insular Gran Canaria, Las Palmas de Gran Canaria); Mena A, MD (Hospital Dr Negrín, Las Palmas de Gran Canaria); Moraleda S, MD (Hospital La Paz, Madrid); Pacheco M, MD (Hospital de Cruces, Baracaldo); Pinedo S, MD (Hospital de Górliz, Vizcaya); Roda C, MD (Hospital La Fe, Valencia); Sánchez J, MD (Hospital Puerta del Mar, Cádiz); Sanchez MJ (Hospital Marqués de Valdecilla, Santander); Sevilla A, MD (Hospital Virgen de la Victoria, Málaga); Tirado M, MD (Hospital Carlos Haya, Málaga); Valls-Solé J, MD (Hospital Clínic, Barcelona). We extend our gratitude to the patients, without whom this study would not have been possible. The authors thank Watermeadow Medical, an Ashfield company for providing help with medical writing and editorial support, sponsored by Ipsen in accordance with Good Publication Practice guidelines.

\section{Statement of Ethics}

All participating patients provided written informed consent. The study was approved by the Spanish Medicine Agency as a postauthorization study with prospective follow-up. It was also approved by the Ethics Committees of all participating sites. Patients' personal data were confidential and delivered to third parties ac- cording to European Directive 95/46/CE on the protection of persons regarding personal data processing and Spanish Law 15/1999 on Personal Data Protection.

\section{Disclosure Statement}

L.L.M. and J.V.-S. have been investigators in Ipsen-sponsored clinical trials (including the presented VALGAS study), and they or the institutions where they are affiliated have received payment for participation. I.G.P. and P.M. are employees of Ipsen Pharma.

\section{Funding Sources}

This study was sponsored by Ipsen Pharma S.A.

\section{Author Contributions}

All authors made a substantial contribution to the concept and design of the study, acquisition of data, critical revision of the draft and interpretation of data, and provided approval of the present version for submission to publication.

\section{Data Availability}

Where patient data can be anonymized, Ipsen will share all individual participant data that underlie the results reported in this article with qualified researchers who provide a valid research question. Study documents, such as the study protocol and clinical study report, are not always available. Proposals should be submitted to DataSharing@Ipsen.com and will be assessed by a scientific review board. Data are available beginning 6 months and ending 5 years after publication; after this time, only raw data may be available.

\section{References}

1 Donnan GA, Fisher M, Macleod M, Davis SM. Stroke. Lancet. 2008 May;371(9624): 1612-23.

2 Feigin VL. Stroke epidemiology in the developing world. Lancet. 2005 Jun;365(9478): 2160-1.

3 Díaz-Guzmán J, Bermejo-Pareja F, BenitoLeón J, Vega S, Gabriel R, Medrano MJ; Neurological Disorders in Central Spain (NEDICES) Study Group. Prevalence of stroke and transient ischemic attack in three elderly populations of central Spain. Neuroepidemiology. 2008;30(4):247-53.

4 Esquenazi A, Albanese A, Chancellor MB, Elovic E, Segal KR, Simpson DM, et al. Evidence-based review and assessment of botulinum neurotoxin for the treatment of adult spasticity in the upper motor neuron syndrome. Toxicon. 2013 Jun;67:11528.

5 Esquenazi A, Mayer NH, Elia AE, Albanese A. Botulinum toxin for the management of adult patients with upper motor neuron syndrome. Toxicon. 2009 Oct;54(5):634-8.

6 Lundström E, Terént A, Borg J. Prevalence of disabling spasticity 1 year after first-ever stroke. Eur J Neurol. 2008 Jun;15(6):533-9.

7 Watkins CL, Leathley MJ, Gregson JM, Moore AP, Smith TL, Sharma AK. Prevalence of spasticity post stroke. Clin Rehabil. 2002 Aug; 16(5):515-22.

8 Cioni M, Esquenazi A, Hirai B: Effects of botulinum toxin-A on gait velocity, step length, and base of support of patients with dynamic equinovarus foot. Am J Phys Med Rehabil. 2006 Jul;85(7):600-6.

9 Ferreira LA, Neto HP, Grecco LA, Christovão TC, Duarte NA, Lazzari RD, et al. Effect of Ankle-foot Orthosis on Gait Velocity and Cadence of Stroke Patients: A Systematic Review. J Phys Ther Sci. 2013 Nov;25(11):15038.

10 Ward AB. Spasticity treatment with botulinum toxins. J Neural Transm (Vienna). 2008; 115(4):607-16

11 Royal College of Physicians, British Society of Rehabilitation Medicine, Chartered Society of Physiotherapy, Association of Chartered Physiotherapists Interested in Neurology: Spasticity in adults: management using botulinum toxin. National guidelines, 2018. 
12 Wissel J, Ward AB, Erztgaard P, Bensmail D, Hecht MJ, Lejeune TM, et al. European consensus table on the use of botulinum toxin type A in adult spasticity. J Rehabil Med. 2009 Jan;41(1):13-25.

13 Simpson DM, Gracies JM, Graham HK, Miyasaki JM, Naumann M, Russman B, et al.; Therapeutics and Technology Assessment Subcommittee of the American Academy of Neurology. Assessment: Botulinum neurotoxin for the treatment of spasticity (an evidence-based review): report of the Therapeutics and Technology Assessment Subcommittee of the American Academy of Neurology. Neurology. 2008 May;70(19):1691-8.

14 Simpson DM, Hallett M, Ashman EJ, Comella CL, Green MW, Gronseth GS, et al. Practice guideline update summary: Botulinum neurotoxin for the treatment of blepharospasm, cervical dystonia, adult spasticity, and headache: Report of the Guideline Development Subcommittee of the American Academy of Neurology. Neurology. 2016 May; 86(19):1818-26.

15 Gracies JM, Esquenazi A, Brashear A, Banach M, Kocer S, Jech R, et al.; International AbobotulinumtoxinA Adult Lower Limb Spasticity Study Group. Efficacy and safety of abobotulinumtoxinA in spastic lower limb: randomized trial and extension. Neurology. 2017 Nov;89(22):2245-53.

16 Krasny-Pacini A, Hiebel J, Pauly F, Godon S, Chevignard M. Goal attainment scaling in rehabilitation: a literature-based update. Ann Phys Rehabil Med. 2013 Apr;56(3):212-30.

17 Turner-Stokes L, Fheodoroff K, Jacinto J, Maisonobe P. Results from the Upper Limb
International Spasticity Study-II (ULISII):a large, international, prospective cohort study investigating practice and goal attainment following treatment with botulinum toxin $\mathrm{A}$ in real-life clinical management. BMJ Open. 2013 Jun;3(6):e002771.

18 Goal attainment scaling: Applications, theory, and measurement. Hillsdale, NJ, US: Lawrence Erlbaum Associates, Inc.; 1994.

19 Bohannon RW, Smith MB. Interrater reliability of a modified Ashworth scale of muscle spasticity. Phys Ther. 1987 Feb;67(2):206-7.

20 Platz T, Kim IH, Engel U, Kieselbach A, Mauritz $\mathrm{KH}$. Brain activation pattern as assessed with multi-modal EEG analysis predict motor recovery among stroke patients with mild arm paresis who receive the Arm Ability Training. Restor Neurol Neurosci. 2002;20(1-2):21-35.

21 SAS Institute Inc. SAS/QC ${ }^{\circledR}$ 9.2: User's Guide, ed Second Edition. Cary, NC, USA: SAS Institute Inc.; 2010.

22 Turner-Stokes L. Goal attainment scaling (GAS) in rehabilitation: a practical guide. Clin Rehabil. 2009 Apr;23(4):362-70.

23 Turner-Stokes L, Baguley IJ, De Graaff S, Katrak P, Davies L, McCrory P, et al. Goal attainment scaling in the evaluation of treatment of upper limb spasticity with botulinum toxin: a secondary analysis from a doubleblind placebo-controlled randomized clinical trial. J Rehabil Med. 2010 Jan;42(1):81-9.

24 Turner-Stokes L, Williams H, Johnson J. Goal attainment scaling: does it provide added value as a person-centred measure for evaluation of outcome in neurorehabilitation following acquired brain injury? J Rehabil Med. 2009 Jun;41(7):528-35.
25 Clemenzi A, Formisano R, Matteis M, Gallinacci L, Cochi G, Savina P, et al. Care management of spasticity with botulinum toxin-A in patients with severe acquired brain injury: a 1 -year follow-up prospective study. Brain Inj. 2012;26(7-8):979-83.

26 Fheodoroff K, Ashford S, Jacinto J, Maisonobe P, Balcaitiene J, Turner-Stokes L. Factors influencing goal attainment in patients with post-stroke upper limb spasticity following treatment with botulinum toxin $\mathrm{A}$ in reallife clinical practice: sub-analyses from the Upper Limb International Spasticity (ULIS)II Study. Toxins (Basel). 2015 Apr;7(4):1192205.

27 Jost WH, Hefter H, Reissig A, Kollewe K, Wissel J. Efficacy and safety of botulinum toxin type A (Dysport) for the treatment of poststroke arm spasticity: results of the GermanAustrian open-label post-marketing surveillance prospective study. J Neurol Sci. 2014 Feb;337(1-2):86-90.

28 Mohammadi B, Balouch SA, Dengler R, Kollewe K. Long-term treatment of spasticity with botulinum toxin type A: an analysis of 1221 treatments in 137 patients. Neurol Res. 2010 Apr;32(3):309-13.

29 electronic Medicines Compendium (eMC) (ed): Dysport 300 units SmPC, 2019. https:// www.medicines.org.uk/emc/product/964/ smpc.

30 Foley N, Murie-Fernandez M, Speechley M, Salter K, Sequeira K, Teasell R. Does the treatment of spastic equinovarus deformity following stroke with botulinum toxin increase gait velocity? A systematic review and meta-analysis. Eur J Neurol. 2010 Dec;17(12):1419-27. 